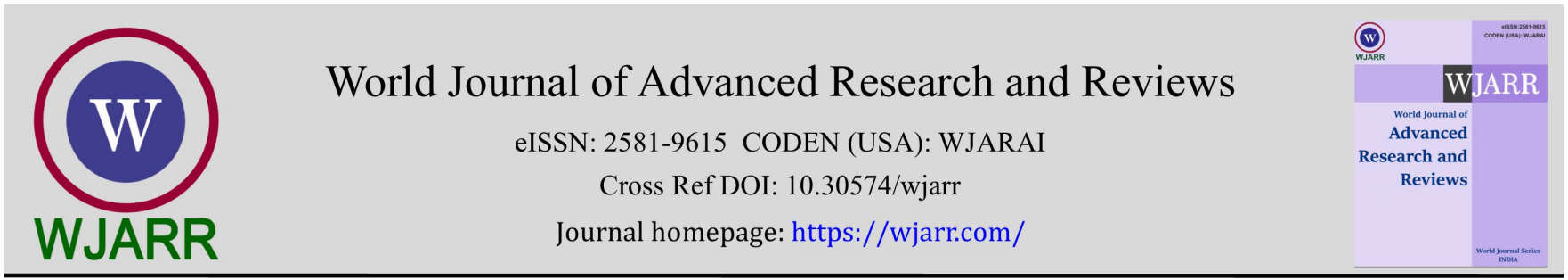

(CASE REPORT)

Check for updates

\title{
Idiopathic clitoromegaly: Reduction clitoroplasty at Al-Rahma Hospital Zanzibar Tanzania: A case report and review of the literature
}

\author{
Mohammed Mbarouk ${ }^{1,}{ }^{*}$, Fatuma Lijohi ${ }^{2}$, AK Mteta ${ }^{3}$, Samuel Kibona ${ }^{4}$ and Emanuel Itambu 5 \\ ${ }^{1}$ Department of Urology, Al-Rahma Hospital, P.O. Box 281, Zanzibar, Tanzania. \\ 2 Department of Obstetrics and Gynaecology, Al-Rahma Hospital, P.O. Box 281, Zanzibar, Tanzania. \\ ${ }^{3}$ Department of Urology, Faculty of Medicine, Kilimanjaro Christian Medical University College, P.O. Box 2240, Moshi, \\ Tanzania. \\ ${ }^{4}$ Department of Urology, Mzinga Military Hospital, P.O. Box 737, Morogoro, Tanzania. \\ 5 Department of Urology, Arusha Hospital P. O. Box 1489 Arusha, Tanzania.
}

World Journal of Advanced Research and Reviews, 2021, 11(02), 276-279

Publication history: Received on 29 June 2021; revised on 18 August 2021; accepted on 20 August 2021

Article DOI: https://doi.org/10.30574/wjarr.2021.11.2.0361

\begin{abstract}
We present a case of 5 years old female with of idiopathic clitoromegaly managed by reduction clitoroplasty, preserving the dorsal neurovascular bundle and extensive network of nerves around the corpora to the glans Clitoromegaly is an embarrassing condition causing psychological stress, requiring intervention. The goals of clitoroplasty are to achieve normal genital anatomy and to preserve tactile sensation with a satisfactory sexual response.
\end{abstract}

Keywords: Clitoris; Clitoromegaly; Reduction; Clitoroplasty

\section{Introduction}

Clitoromegaly may be congenital or acquired, as clitoral area $35-45 \mathrm{~mm}^{2}$ (length $\times$ width). It can be a result of congenital adrenal hyperplasia or mixed gonadal dysgenesis. The objectives of clitoroplasty are preservation of sexual arousal function and sensation, and cosmetic [1].

\section{Case Description}

This girl presented at the age of 5 years with complaints of an enlarged clitoris. Upon examination of the genitalia showed an enlarged clitoris resembling penis. The labia majora were normal with no rugosity but had fusion at fourchette and the labia minora were redundant. The urethral meatus was normal located. The introitus was normal with the presence of hymenal ring. Clitoromegaly was significant with a penile appearance. Clitoral length measured 3.8 and $5 \mathrm{~cm}$ without and with stretching, respectively, in the nonarousal state with some hair surrounding it. Karyotyping revealed that patient was genotypically a normal female (46XX). Ultrasound examination of the abdomen and pelvis did not reveal adrenal hyperplasia and uterus; cervix and both ovaries were normal. a cystoscopy done revealed a normal urethral, normal bladder neck, no veru seen with normal bladder mucosa. Her FSH (5.79 mIU $/ \mathrm{ml}), \mathrm{LH}(7.44 \mathrm{mIU} / \mathrm{ml})$, prolactin $(8.65 \mathrm{ng} / \mathrm{ml})$ oestrogen $(12 \mathrm{pg} / \mathrm{ml})$, testosterone $(3.08 \mathrm{ng} / \mathrm{ml})$ and progesterone(1ng/ml) were normal. A diagnosis of Idiopathic clitoral hypertrophy was made. She was taken to theatre for nerve preserving reduction clitoroplasty.

\footnotetext{
${ }^{*}$ Corresponding author: Mohammed Mbarouk

Department of Urology, Al-Rahma Hospital, P.O. Box 281, Zanzibar, Tanzania.

Copyright $(2021$ Author(s) retain the copyright of this article. This article is published under the terms of the Creative Commons Attribution Liscense 4.0.
} 
Surgery was performed under general anaesthesia in lithotomy position with thighs abducted, legs well supported on padded stirrups. An indwelling urinary catheter was put in and a stay suture placed on the glans clitoris to ease its handling and to keep it in traction.

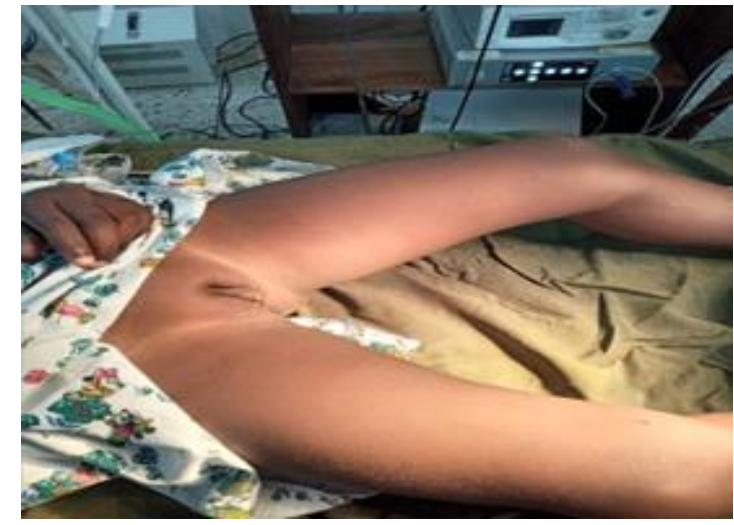

Figure 1 Enlarged clitoris and glans

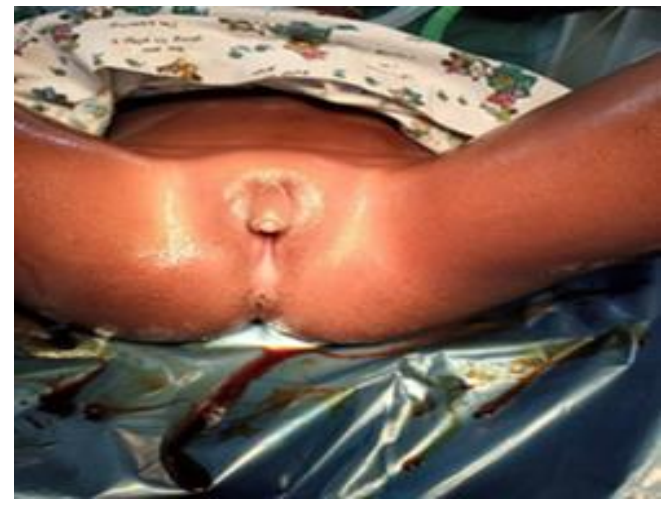

Figure 2 Patient in lithotomy position

\section{Surgical Procedure}

A circumferential incision was marked $1 \mathrm{~cm}$ proximal to corona on the inner prepucial layer,stay suture was kept at the glans. The clitoris was degloved till its roots, but the skin envelope was left attached proximally at this stage. Care was taken to keep all soft tissue of the dorsal $1 \mathrm{~cm}$ wide strip on the tunica albuginea and on the side of corpora on dorsum to safeguard the neurovascular pedicle. Once the corpora were dissected from the dorsal NV pedicle containing strip, till their bifurcation under the symphysis pubis, tourniquet was used to achieved a haemostat.

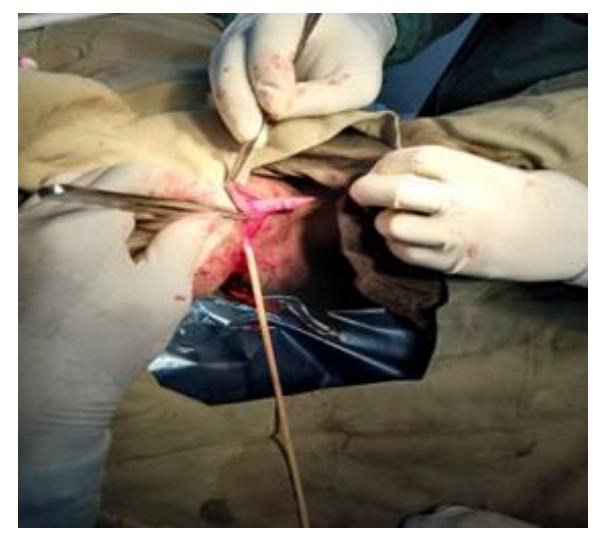

Figure 3 Circumferential skin incision has been given. A stay suture has been placed in the glans clitoris. A Foley catheter exits from the urethra

\section{Glans Anchoring}

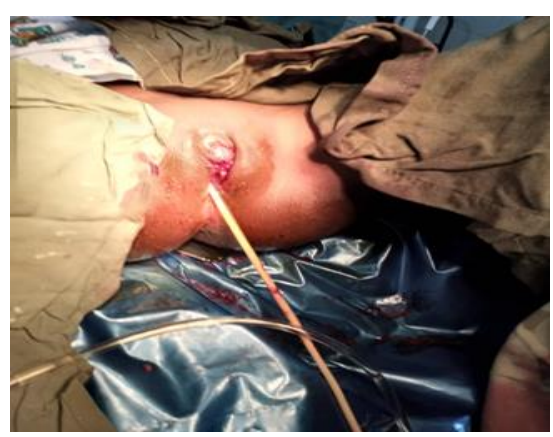

Figure 4 Immediate postoperative image showing Neo Clitoris, Neo labial minora creation 
This is done by two sutures of 3-0 prolyne taken from dorsal and lateral margins of dorsal NV strip near glans and anchored at the depth by a deep bite through soft tissue on the under surface of symphysis pubis. This manoeuvre retracts the glans backwards and upwards in its hood and gives that natural look when the oedema subsides. Patient now has normal appearing genitalia and a sensate clitoris with good preservation of sensation to light touch.

\section{Trimming the Skin}

The degloved skin tube which was left attached proximally is split in mid-dorsal line just $1 \mathrm{~cm}$ short of its base and pulled forward to mark excess to be trimmed was sutured to the skin of the glans with 3-0 Vicryl. This centimetre of mid-dorsal skin gives natural sloping appearance to the neo hood clitoris (Fig 4).

\section{Discussion}

Clitoromegaly refers to the Enlargement of Clitoris, which is a rare Surgical entity. The most common congenital cause is female pseudo hermaphroditism secondary to congenital adrenal hyperplasia (CAH) or adrenogenital syndrome. However, clitoromegaly may be accompanied by fusion of the labioscrotal folds and perineoscrotal hypospadias, and a persistence of the urogenital sinus closing the external opening of the vagina [2].

Kujur et al claim to separate dorsal NV bundle along with the extensive network of nerves to the glans around the end of corporeal bodies. Separating corpora from their apices under the glans clitoris proximally helps in preserving this network and keeping the NV bundle attached to the under surface of Buck's fascia strip dorsally safeguards NV bundle. Therefore, it is very important to perform clitoral reduction through a 'safe ventral channel [3].

However, the preferred technique for many medical centres was the technique described by Kumar et al in 1974 . This technique is characterized by a partial resection of the corpus cavernosum after the release of the dorsal neurovascular pedicle, followed by suturing of the edges using nonabsorbable fine wire. But this technique is responsible for an unacceptable cosmetic appearance with a large glans disproportionate to its surroundings. Both mentioned techniques, do not involve any reduction in the diameter of the corpus cavernosum responsible for a voluminous clitoris during erection [4].

\section{Conclusion}

Idiopathic clitoromegaly is rare with few case reports. The objectives of clitoroplasty are preservation of sexual arousal function and sensation, and cosmetic. Clitoroplasty with preservation of the neurovascular pedicle may be the optimal operative technique for the treatment of clitoromegaly.

\section{Compliance with ethical standards}

\section{Acknowledgments}

We thank the parent of our patient for allowing us to publish this case report. We also extend our sincere gratitude to our photographer for helping us with arranging images in this manuscript

\section{Disclosure of conflict of interest}

All authors declare no conflicts of interest. All authors provide consent for publication. There is no funding to report.

\section{Statement of ethical approval}

This report has received approval for chart review and publication.

\section{Statement of informed consent}

Written informed consent for publication of the case details and accompanying images was obtained from the parent.

\section{References}

[1] Oyama IA, Steinberg AC, Holzberg AS, Maccarone JL. Reduction clitoroplasty: A technique for debulking the enlarged clitoris. J Pediatr Adolesc Gynecol. 2004; 17(6): 393-5. 
[2] Topcuoglu H, Yanik A. International Journal of Medical and Health Sciences. Int J Occup Environ Health. 2014; 2(4): 301-7.

[3] Kujur AR, Joseph V, Chandra P. Nerve sparing clitoroplasty in a rare case of idiopathic clitoromegaly. Indian J Plast Surg. 2016; 49(1): 86-90.

[4] Kumar H, Kiefer JH, Rosenthal IE, Clark SS. Clitoroplasty: experience during a 19 year period. J Urol. 1974; 111(1): 81-4. 